\title{
Intrathecal Baclofen - The Importance of Catheter Position
}

\author{
Herman Hugenholtz, Robert F. Nelson and Eric Dehoux
}

\begin{abstract}
In a patient receiving intrathecal baclofen injections for intractable trunk and leg spasms, positioning the subarachnoid catheter tip just caudal to the spinal segments innervating the spastic muscles enhanced the spasmolytic effect of bolus injections of intrathecal baclofen on the affected muscles. Such selective positioning of subarachnoid catheters may facilitate segmental spasmolysis with lower intrathecal doses of baclofen and provide an important alternative to relying only on ascending CSF concentration gradients of baclofen from chronic lumbar intrathecal infusion.

RÉSUMÉ: Importance de la position du cathéter dans l'administration intrathécale du baclofen. La localisation de l'extrémité du cathéter en position caudale par rapport aux segments spinaux innervant les muscles spastiques a amplifié l'effet spasmolytique d'injections intrathécales en bolus de baclofen sur les muscles atteints chez un patient recevant ces injections pour des spasmes réfractaires au traitement au niveau du tronc et des jambes. Une localisation sélective des cathéters sous-arachnoïdiens peut faciliter la spasmolyse segmentaire avec des doses plus faibles de baclofen intrathécal. Cette stratégie constitue une alternative très valable à l'infusion intrathécale chronique de baclofen au niveau lombaire où l'on se fie uniquement à la diffusion ascendante du médicament dans le liquide céphalorachidien.
\end{abstract}

Can. J. Neurol. Sci. 1993; 20: 165-167

The direct application of baclofen (Lioresal) into the spinal subarachnoid space avoids the dose-limiting side effects of its oral administration. Since baclofen is water-soluble and baclofen-sensitive GABA-B receptors are located in the superficial layers of the spinal cord, ${ }^{1}$ infusing baclofen into the spinal CSF allows small amounts of baclofen to reach these receptors in a manner similar to that described for intrathecal morphine. ${ }^{2,3}$

The spasmolytic effect of intrathecal baclofen is doserelated. ${ }^{4}$ The baclofen dose can be titrated to reduce spasticity in an ascending segmental fashion and to maintain sufficient motor power and tone for transfers and ambulation. ${ }^{5-11}$

In order to maintain a consistent therapeutic effect from chronic intrathecal infusion, it is essential that the catheter remains in the subarachnoid space. Most of these patients are ambulatory and active and therefore vulnerable to catheter dislodgement. Dislodgement can be minimized by introducing a sufficient length of catheter into the subarachnoid space and by anchoring the catheter. ${ }^{11.12}$

While a sufficient drug concentration is required at the affected spinal segments, it is imperative to minimize the amount of drug that will reach the cervical subarachnoid space and the intracranial subarachnoid cisterns in order to avoid respiratory failure and coma. Normally, substances introduced into the lumbar subarachnoid space ascend to the cranial cisterns. ${ }^{13}$
Chronic infusion of drugs into the lumbar subarachnoid space creates a lumbar to cranial CSF concentration gradient. 2.9 .14

The position of the catheter tip may influence the distribution of the intrathecal baclofen but the importance of the position of the catheter tip in relation to the spinal segments has received little attention. Lumbar subarachnoid infusion is ideal for control of trunk and leg spasms. To preserve voluntary motor power and sufficient tone to facilitate transfers, one must either use very low doses of baclofen and accept some persistent spasms, or one must pursue other strategies such as selective positioning of the catheter tip above the spinal segments that mediate preserved tone and voluntary movement. Observations during the treatment of one of our patients with intrathecal baclofen for spasticity suggest that the position of the catheter tip may be more important than previously recognized.

\section{Case Report}

A 31-year-old woman with post-encephalomyelitic optic atrophy, impairment to all sensory modalities below T4, urinary and fecal incontinence and a paraparesis presented with intractable painful spasms of her trunk and both legs that could not be controlled with intensive daily physiotherapy and oral spasmolytic agents. A combination of $120 \mathrm{mg}$ of baclofen and $40 \mathrm{mg}$ of valium made her intolerably drowsy.

Patency of her spinal and cranial subarachnoid spaces was confirmed with MRI. No intrinsic spinal cord lesions could be identified.

From the Departments of Neurosurgery (H.H.), and Neurology (R.F.N.), Ottawa General Hospital; and Rehabilitation Medicine, Royal Ottawa Rehabilitation Centre, Ottawa

Received July 22, 1992. Accepted in final form November 23, 1992

Reprint requests to: Herman Hugenholtz, M.D., Room 6353, Ottawa General Hospital, 501 Smyth Road, Ottawa, Ontario, Canada KIH 8L6 
She was weaned from her oral spasmolytic medications over seven days and given a test dose of $10 \mu \mathrm{g}$ of baclofen into her lumbar subarachnoid space by lumbar puncture in order to exclude any untoward reactions. A bolus of $20 \mu \mathrm{g}$ of intrathecal baclofen via lumbar puncture at the L3.4 interspace produced a reduction in tone and spasms in the lower limbs and trunk for six hours. Forty microgram bolus injections of intrathecal baclofen resulted in satisfactory spasmolysis of the trunk and lower limbs with preservation of voluntary motor movement.

A subarachnoid catheter was then introduced at the L3-4 interspace and its tip was advanced to T6 as a strategy to preserve some tone and voluntary power in her legs and to diminish the possibility of subsequent catheter migration out of the subarachnoid space. The catheter was connected to a subcutaneous catheter access port (CAP Infusaport, Shiley Infusaid). Our double-blind crossover paradigm of bolus injections was then followed, alternating bolus injections of saline and of $40 \mu \mathrm{g}$ of baclofen into the CAP in order to confirm that the spasmolytic effect could be attributed only to baclofen. ${ }^{5}$

To our surprise, none of the bolus injections during this crossover phase produced any therapeutic effect even though two of those injections contained $40 \mu \mathrm{g}$ of baclofen, nor did subsequent bolus injections of $40 \mu \mathrm{g}$ of known baclofen solution. Therefore, a myelogram was performed which confirmed not only that the thoraco-lumbar subarachnoid space was patent, but that the catheter tip was definitely in the subarachnoid space, opposite the body of T6. Following this myelogram three consecutive bolus injections of $40 \mu \mathrm{g}$ of baclofen solution into the lumbar subarachnoid space by lumbar puncture produced satisfactory spasmolysis in the trunk and lower limbs of seven hours' duration after each injection. On the other hand, additional bolus injections of $40 \mu \mathrm{g}$ of baclofen through the CAP had no effect.

Therefore, the catheter tip was repositioned in the subarachnoid space opposite the T10-11 disc space and the catheter was connected to a Model 400 Infusaid pump (Shiley Infusaid). Three consecutive bolus injections of $40 \mu \mathrm{g}$ of baclofen through the pump side port produced satisfactory clinical spasmolysis in the trunk and lower limbs. Chronic infusion at $175 \mu \mathrm{g}$ of baclofen per 24 hours was then started and the patient was discharged from hospital 72 hours later with satisfactory spasmolysis.

However, despite gradual escalations of her baclofen dose from 175 to $800 \mu \mathrm{g}$ per day over an interval of 5 months, we were unable to reproduce the striking spasmolysis observed following the initial $40 \mu \mathrm{g}$ lumbar subarachnoid bolus injections and the initial 72 hours of chronic infusion of $175 \mu \mathrm{g} /$ day. Additional radiographic studies confirmed that the catheter tip remained opposite the T10-11 disc space in the centre of the spinal canal.

On the presumption that the catheter tip was still too cephalad to deliver adequate baclofen concentrations to the spinal segments mediating her trunk and lower limb spasticity, the catheter was repositioned a second time so that the catheter tip rested in the subarachnoid space opposite the first lumbar vertebral body. Since then, chronic infusion of intrathecal baclofen at $800 \mu \mathrm{g} /$ day, has provided satisfactory spasmolysis in the trunk and lower limbs for the three consecutive months to the time of this communication.

\section{Discussion}

Baclofen introduced directly into the lumbar subarachnoid space diffuses cephalad along the spinal cord, assisted by CSF bulk flow. ${ }^{13}$ Therefore, in order to reduce the risk of inadvertent overdose from excessive intracranial baclofen concentrations, most investigators position the subarachnoid catheters in the lumbar subarachnoid space but seldom specify exactly where the subarachnoid catheter tips are located.

Some investigators advance the catheters cephalad from the point of insertion, while others direct them caudally. ${ }^{2.7 .12}$ Loubser et al. ${ }^{6}$ and $O \mathrm{Ochs}^{8}$ routinely advance their catheters to the thoracolumbar junction as an additional measure to prevent dislodgement from the subarachnoid space.

One would anticipate that baclofen injected or infused at the mid-thoracic level would ascend in a cephalad direction away from spinal segments mediating trunk and leg spasms.
Nevertheless, Muller-Schwefe and Penn ${ }^{15}$ and Ochs et al. ${ }^{12}$ found that the predominant spasmolytic effect ocurred in the lower limbs from bolus doses of baclofen through a catheter with its tip at T6. This suggests that with large doses of baclofen, concentrations sufficient to induce spasmolysis can still be achieved in the region of the conus. There may also be variations in the intensity and direction of CSF bulk flow, especially after interventions in the subarachnoid space, which may affect the diffusion of baclofen.

Ideally, the catheter tip should be placed in juxtaposition to the most caudal of the affected spinal segments in order to take advantage of the cephalad CSF bulk flow. ${ }^{13}$ Bolus injections with barbotage may disperse baclofen even further from the catheter tip in a cephalad direction while chronic infusion is more likely to create a stable CSF concentration gradient. ${ }^{2}$ Our observations support the premise that the intrathecal baclofen should preferably be administered caudal to the lowest affected spinal segment of the spinal cord, regardless of its method of administration. Advancing the catheter tip all the way to T6 as a strategy to minimize catheter dislodgement, proved to be counterproductive for our patient.

Spasmolysis in individuals with intractable upper limb spasms but with preservation of some useful lower limb tone or motor power is difficult. The baclofen dose can certainly be titrated to create an ascending CSF concentration gradient in order to deliver sufficient baclofen to the receptors in the lower cervical spinal segments. ${ }^{9}$ But, in order to achieve satisfactory spasmolysis in the upper limbs, it is often necessary to sacrifice tone and power in the lower limbs even to the point of flaccid paralysis. To reduce spasticity in the upper part of the body without sacrificing tone and remaining motor power in the legs, alternate strategies need to be developed.

Our observations suggest that selective positioning of one or more catheter tips just caudal to the spinal segments selected for spasmolysis may be appropriate in such instances as a means of using low doses delivered in juxtaposition to the affected spinal segments. Muller-Schwefe and Penn ${ }^{15}$ intentionally advanced a subarachnoid catheter tip to T6 in a subject in an attempt to control spasticity in both the upper and the lower limbs. They noted spasmolysis in the lower limbs but did not comment on whether spasmolysis was achieved in the upper limbs or not. Unfortunately, their patient suffered an overdose which was more likely the result of the large $150 \mu \mathrm{g}$ bolus dose of baclofen rather than from the catheter position.

While we are unaware of reports of cervical intrathecal baclofen injections for the selective control of upper limb spasticity, Ventafridda et al. ${ }^{16}$ administered morphine directly into the cervical subarachnoid space to control intractable cervicobrachial pain in cancer patients. Jones et al. ${ }^{17}$ employed epidural baclofen injections at the C7-T1 level without complications and controlled the spasticity in a partial quadriplegic patient. However, the pharmacodynamics of epidural injections of water-soluble drugs differ considerably from those following intrathecal injections. ${ }^{18}$

We acknowledge that our observations represent only an anecdote to published reports of intrathecal baclofen treatment. In our patient, introducing the baclofen in juxtaposition to the spinal segments innervating the spastic muscle groups dramatically enhanced its spasmolytic effect, suggesting that smaller doses infused near the spinal segments innervating the spastic 
muscles may avoid dependence on ascending segmental concentration gradients from large doses in the lumbar region. We suggest that such strategy warrants further study in subjects afflicted with intractable upper limb spasticity where preservation of tone and power in the lower limbs is functionally important to a particular subject.

\section{ACKNOWLEDGEMENT}

CIBA-GEIGY Canada Ltd provided the baclofen (Lioresal) solution.

\section{REFERENCES}

1. Price GW, Wilkin GP, Turnbull MJ, Bowery NG. Are baclofen-sensitive GABA receptors present on primary afferent terminals of the spinal cord? Nature 1984; 307: 71-74.

2. Penn RD, Kroin JS. Long-term intrathecal baclofen infusion for treatment of spasticity. J Neurosurg 1987; 66: 181-185.

3. Yaksh TL. Spinal opiate analgesia: characteristics and principles of action. Anaesthesiology 1981; 61:293-346.

4. Dralle D, Muller H, Zeirski J. Lumber intrathecal baclofen for cerebral palsy in children. The Physician India 1988; 4: 153-156.

5. Hugenholtz H, Nelson RF, Dehoux E, Bickerton R. Intrathecal baclofen for intractable spinal spasticity - a double-blind crossover comparison of 6 patients. Can J Neurosci 1992; 19: 188195.

6. Loubser PG, Narayan RK, Sandin KJ, Donovan WH, Russell KD. Continuous infusion of intrathecal baclofen: long-term effects on spasticity in spinal cord injury. Paraplegia 1991; 29: 48-64.

7. Muller $\mathrm{H}$, Zeirski J. Long-term continuous intrathecal baclofen infusion. In: Marsden CD, ed. Treating Spasticity: Pharmacological Advances. Toronto: Hans Huber 1989; 55-68.
8. Ochs G, Struppler A, Meyerson BA, et al. Intrathecal baclofen for long-term treatment of spasticity: a multicentre study. J Neurol Neurosurg Psychiatry 1989; 52: 933-939.

9. Penn RD, Savoy SN, Corcos D, et al. Intrathecal baclofen for severe spinal spasticity. N Engl J Med 1989; 320: 1517-1521.

10. Stewart-Wynne EG, Hankey GJ, Perlman D. A place for intrathecal 'Lioresal' in spasticity. I $m$ : Jones R, ed. Lioresal: An Update. North Rock: Neil Duncan 1988; 6-7.

11. Zierski J, Muller H, Dralle D, Wurdinger T. Implanted pump systems for treatment of spasticity. Acta Neurochir Suppl 1988; 43: 94-99.

12. Ochs G. Intrathecal application of baclofen (Lioresal) in spasticity, In: Marsden CD, ed. Treating Spasticity: Pharmacological Advances. Toronto: Hans Huber 1989; 49-54.

13. di Chiro G. Observations on the circulation of the cerebrospinal fluid. Acta Radiologica 1966; 5: 988-1002.

14. Coombs DW, Fratkin JD, Meier F, Nierenberg DW, Saunders RL. Neuropathologic lesions and CSF morphine concentrations during chronic continuous intraspinal morphine infusion. A clinical and post-mortem study. Pain 1985; 22: 337-351.

15. Muller-Schwefe G, Penn RD. Physostigmine in the treatment of intrathecal baclofen overdose. J Neurosurg 1989; 71: 273-275.

16. Ventafridda V, Figliuzzi M, Tamburini M, et al. Clinical observation on analgesia elicited by intrathecal morphine in cancer patients. In: Bonica JJ, Liebeskind JC, Albe-Fessard DG, eds. Advances in Pain Research and Therapy. New York: Raven 1979; 559-565.

17. Jones RF, Anthony M, Torda TA, Poulos C. A place for epidural Lioresal in spasticity. In: Jones RF, ed. Lioresal: An Update. North Rocks: Neil Duncan 1988; 8-11.

18. Cousins MJ, Mather LE. Intrathecal and epidural administration of opiates. Anaesthesiology 1984; 61: 276-310. 